\title{
CLASSIFYING FLEXIBILITY TYPES IN SMART ELECTRIC DISTRIBUTION GRIDS: A TAXONOMY
}

\author{
Rieke B ÄRENFÄNGER \\ University of St. Gallen - Switzerland \\ rieke.baerenfaenger@unisg.ch
}

\author{
Elisabeth DRAYER \\ University of Kassel - Germany \\ elisabeth.drayer@uni-kassel.de
}

\author{
Damian DANILUK, Boris OTTO \\ Fraunhofer IML - Germany \\ boris.otto@iml.fraunhofer.de
}

\author{
Emmanuelle VANET, Raphael CAIRE \\ G2Elab Grenoble INP - France \\ emmanuelle.vanet@g2elab.grenoble-inp.fr, \\ raphael.caire@g2elab.grenoble-inp.fr
}

\author{
Tayyab SHAMSI ABBAS, Bruno LISANTI \\ ActValue - Italy \\ tayyab.shamsi@actvalue.com, \\ bruno.lisanti@actvalue.com
}

\begin{abstract}
This paper proposes a classification scheme for the different types of flexibilities that are used in electric grids. This classification scheme, which is called a taxonomy, helps to convey the meaning of different concepts of flexibility in research and industrial projects. It also allows to compare the sources and uses of flexibility in conventional vs. smart grid situations to highlight the evolving nature of the power system.
\end{abstract}

\section{INTRODUCTION}

The increasing use of distributed energy resources (DER) in electricity distribution markets can make the distribution system more stable and efficient. This requires that the flexibility derived from controllable consumption and/or generation of local grid devices such as electric vehicles, heat pumps, PV, or wind turbines can be actively managed. Many solutions are currently being developed that aim at making these flexibilities available for the energy markets [1].

However, the experience in DREAM $^{1}$, an ongoing research project about the exploitation of distributed renewable resources in electric grids through advanced heterarchical management, shows that "flexibility" is no unambiguous concept in smart distribution grids. In fact, any mechanism designed for a particular use case, for example a use case addressing a specific actor in a specific grid level in a specific time horizon, will be based on its very own understanding of flexibility.

This paper proposes a flexibility description and classification methodology, also called "taxonomy", which allows to unambiguously define the type of flexibility used by a specific smart grid use case from the perspective of the context in which the flexibility occurs. We also list and define main flexibility types that are required for advanced heterarchical management in the distribution grid and distinguish them from conventional flexibilities. One goal

1 DREAM is a project funded by the European Commission under FP7 grant agreement 609359. of the taxonomy is to remove communication barriers in large smart grid research and practical implementation projects. They can be caused by implicit assumptions of a use case developer about the use case context, which are not shared with other partners. The systematic and clear classification of flexibilities explicates the unique characteristics of the type of flexibility at hand. This also helps to distinguish one smart grid solution from another and from conventional ones. It may thereby speed up implementation of new mechanisms in the field and improve the transferability of results from one project to another. Finally, it may also help commercial actors to position their new products and solutions.

The paper proceeds as follows. The following section summarizes related work in the field of flexibility categorization. The next section presents the taxonomy and explains its dimensions. Subsequently, we give an example for the application of the taxonomy from the DREAM research project and the final section concludes the paper.

\section{RELATED WORK}

Generally, flexibility in the context of smart grids is defined as "the extent to which a power system can modify electricity production or consumption in response to variability, expected or otherwise" [2, p. 205]. Similarly, in the DREAM project, flexibility is understood as "the ability of certain devices/elements in the grid to deliberately change their consumption and/or generation patterns within technical constraints" [3, p. 16]. In a smart grid context with virtual power plant-type of aggregators, flexibility may also refer to aggregated end-user flexibilities that aggregators offer to the markets.

Flexibility is already used in conventional electricity systems, for example to meet peak demands. However, unlike conventional power plants, DER such as wind turbines or solar panels have variable production patterns, which increases the need for smarter management of the electricity flows and thus for a better management of flexibility. Because of this growing demand, many research projects, industrial cooperations, and commercial and public actors currently develop new smart grid 
solutions building on flexibility [1]. Some of them also discuss different uses or origins of flexibility. What is missing, however, is a complete description and classification scheme that accommodates all the different possible types of flexibilities for easier identification and sharing of use cases and technical solutions.

One recent example of an existing classification and overview of flexibilities is given in [4]. In this report, the authors list 18 "flexibility services" [4, p.19], which are assigned to five different actors in the system. These flexibility services are in fact different purposes or usage scenarios of flexibilities, for example congestion management, intraday optimization, or primary control.

In contrast, the authors of [5] only list three possible "uses of flexibility": portfolio optimization (by market players to fulfill their energy obligations at lowest possible costs), balancing (procurement of balancing services and activation of balancing energy), and constraints management in transmission and distribution networks (by network operators to ensure quality of supply) [5, p.5].

The authors of [2] describe additional dimensions of the flexibility concept. They distinguish the "needs for flexibility" (reasons like demand variability or contingencies), the "power system context" (power market, system operations, etc.), and the type of "flexible resources" (power generation plants, demand side management and response, etc.) [2, p. 205]. Moreover, they divide flexibility into the three categories stability, balancing, and adequacy and mention that these flexibilities fall into different time frames.

This overview shows that there are many different categories or dimensions to be distinguished with respect to flexibilities. Furthermore, terminologies for one and the same type of flexibility may differ from one market or regulatory context to the other. We therefore perceived the need for an objective description and classification scheme.

\section{A TAXONOMY FOR FLEXIBILITIES IN SMART GRIDS}

\section{Taxonomy development}

A taxonomy is "a system for grouping objects of interest in a domain based on common characteristics" [6, p. 338]. The different categories in this system are called dimensions (e.g., "grid level") and the manifestations or options within each dimension are called characteristics (e.g., "high voltage" (HV) or "low voltage" (LV)).

The authors of [6] describe several principles for a useful taxonomy. Firstly, it should be concise and only have a limited number of dimensions and of characteristics.
Secondly, it should be robust, which means it should be able to clearly distinguish the objects of interest. Thirdly, they should be comprehensive or complete and be able to cover all relevant objects of interest. Fourthly, it should be extendible by further dimensions and characteristics to be adaptable to new developments. Finally, it should be explanatory, meaning it should go beyond just being descriptive and help the user or reader understand the objects of interest. We kept these principles for useful taxonomies in mind to develop our taxonomy for flexibility types in electric grids. It is based on two main knowledge sources. On the one hand, it builds on the existing classifications of flexibilities mentioned before and on the other hand on the insights from the DREAM project, which covered several flexibility types in the different use cases.

\section{Taxonomy description}

The proposed taxonomy contains ten dimensions, each with two to six characteristics (see Figure 1). The dimensions are grouped into three domains. There are six context dimensions, two usage dimensions, and two actor dimensions. One could argue that all dimensions represent context factors, but this sub-categorization proved useful in the project discussions.

Grid level. Firstly, we distinguish three grid levels from which the flexibility may originate. These levels are (a) high voltage (HV), (b) medium voltage (MV), and (c) low voltage (LV).

Physical source. This dimension describes the physical source of the flexibility. The four options are (a) smart flexible power resources (any production or consumption resources connected to the grid that can be adjusted or controlled), (b) conventional flexible power resources (e.g. gas turbines or hydroelectric plants), (c) the network or grid itself (e.g. from tap changers of transformers), and finally (d) "aggregation", a combination of multiple of the other sources that are bundled for further use.

Time frame. This dimension states in which time perspective the flexibility is requested and/or used. The typical options are (a) (near) real-time, (b) intraday, (c) day-ahead, and (d) long-term time frames.

Grid status. This dimension describes in which operation state of the grid the flexibility occurs. The options are (a) normal, (b) critical, and (c) emergency grid statuses.

Declaration / intention. Flexibilities can either (a) be planned and declared in advance as systematic offers or (b) be unplanned and be offered or accessed in spontaneous reaction to a certain context.

Payment basis. Depending on the use case and the market design, flexibility use actors pay for (a) the use of the 


\begin{tabular}{|c|c|c|c|c|c|c|c|}
\hline \multicolumn{8}{|c|}{ Context dimensions } \\
\hline Grid level & \multicolumn{2}{|c|}{ Physical source } & Time frame & Grid status & \multicolumn{2}{|c|}{ Declaration } & Payment \\
\hline $\begin{array}{l}\text { a) } \mathrm{LV} \\
\text { b) } \mathrm{MV} \\
\text { c) } \mathrm{HV}\end{array}$ & \multicolumn{2}{|c|}{$\begin{array}{l}\text { a) smart flexibility } \\
\text { power resource } \\
\text { b) network / grid } \\
\text { c) conventional } \\
\text { flexibility power } \\
\text { resource } \\
\text { d) aggregation }\end{array}$} & $\begin{array}{l}\text { a) (near) real- } \\
\text { time } \\
\text { b) intraday } \\
\text { c) day-ahead } \\
\text { d) long-term }\end{array}$ & $\begin{array}{l}\text { a) normal } \\
\text { b) critical } \\
\text { c) emergency }\end{array}$ & \multicolumn{2}{|c|}{$\begin{array}{l}\text { a) planned } \\
\text { b) unplanned }\end{array}$} & $\begin{array}{l}\text { a) for use } \\
\text { b) for availability }\end{array}$ \\
\hline \multicolumn{4}{|c|}{ Usage dimensions } & \multicolumn{4}{|c|}{ Actor dimensions } \\
\hline \multicolumn{2}{|l|}{ Goal } & \multicolumn{2}{|c|}{ Purpose / use case } & \multicolumn{2}{|l|}{ Source actor } & \multicolumn{2}{|c|}{ Use actor } \\
\hline \multicolumn{2}{|c|}{$\begin{array}{l}\text { a) grid operation } \\
\text { b) energy optimization and } \\
\text { delivery }\end{array}$} & \multicolumn{2}{|c|}{$\begin{array}{l}\text { a) local active power mgmt. } \\
\text { b) global active power mgmt. } \\
\text { c) voltage control } \\
\text { d) power quality support } \\
\text { e) redundancy (n-1) support } \\
\text { f) planned optimization }\end{array}$} & \multicolumn{2}{|c|}{$\begin{array}{l}\text { a) Prosumer (/aggregator) } \\
\text { b) DSO } \\
\text { c) TSO } \\
\text { d) Conventional producer }\end{array}$} & \multicolumn{2}{|c|}{$\begin{array}{l}\text { a) Prosumer } \\
\text { b) Aggregator } \\
\text { c) DSO } \\
\text { d) BRP } \\
\text { e) TSO }\end{array}$} \\
\hline
\end{tabular}

\section{Figure 1-Taxonomy for classification of flexibilities}

flexibility, or for (b) for the availability of flexibility (more for capacity-related cases).

Goal. The general goal of the flexibility introduces the use case-related dimensions of the taxonomy. Roughly speaking, flexibilities are used for either (a) grid operation or (b) for energy optimization and delivery.

Use case purpose. More precisely, five use cases (or purposes) of flexibility that belong to grid operation can be distinguished. These are (a) local active power management (e.g. for congestion), (b) global active power management (e.g. frequency, for primary control), (c) voltage control, (d) power quality support, and (e) redundancy (n-1) support (e.g. for reconfiguration after faults or for maintenance). For the energy optimization goal, the use case is (f) planned portfolio optimization.

Source actor. The source actor is the party who owns the source of physical flexibility. Possible options are (a) the prosumer (either as an individual or as a group, represented by an aggregator), (b) the DSO (e.g. for network-source-type flexibilities), (c) the TSO, or (d) a conventional producer.

Use actor. The use actor is the party which acquires the flexibility in order to use it itself or to distribute it further to the market or to another actor. These may be market players or network operators. The possible characteristics are (a) prosumers like household customers, but also larger commercial DER, (b) aggregator, (c) the DSO, (d), Balanced Responsible Party (BRP), or (e) the TSO.

\section{Use of the taxonomy}

The taxonomy can now be used to compare conventional flexibilities with smart grid flexibilities.
Smart grid solutions allow for a greater variety of combinations of the flexibility taxonomy. In contrast, in the conventional grid, flexibility was usually only available from conventional large power plants to the HV network (GridLevel_c and PhysicalSource_c).

With smart grid solutions, flexibility can be made available to the LV and MV grids from a greater variety of sources like prosumer end devices (PhysicalSource_a), the network itself (PhysicalSource_b), or by a commercial aggregator, who collects and distributes flexibilities from other LV/MV sources to offer it to the market (PhysicalSource_d). Furthermore, in the conventional situation, DSOs were hardly able to conduct near real-time power management on their own (meaning certain configurations of the taxonomy with the use actor DSO (UseActor_c) did not exist). On the other hand, with smart grid solutions, a DSO could use flexibilities from the previously mentioned sources for its grid operations.

\section{EXAMPLE APPLICATION}

In the DREAM project, we used the flexibility categorization to distinguish different use cases and their solution design. Three exemplary use cases (called Flex.1 to Flex.3) had the following flexibility configurations (see Figure 2). Flex.1, the "Near real-time planned prosumer flexibility" is a flexibility declared by the prosumer towards a DSO for near real-time usage as a planned availability. Flex.2, the "Day-ahead aggregator flexibility", denominates flexibility that is aggregated from all the LV prosumers of an LV aggregator. The LV aggregator then offers this flexibility to the MV level aggregator for the day-ahead time schedule. Finally, Flex.3, the "Grid flexibility", describes a flexibility that arises from the grid itself. 


\begin{tabular}{|c|c|c|c|}
\hline $\begin{array}{r}\begin{array}{r}\text { Flex. } \\
\text { types }\end{array} \\
\text { Di- } \\
\text { mensions }\end{array}$ & $\begin{array}{l}\text { Flex.1: } \\
\text { Near real- } \\
\text { time pro- } \\
\text { sumer flex. }\end{array}$ & $\begin{array}{l}\text { Flex.2: } \\
\text { Day-ahead } \\
\text { aggregator } \\
\text { flexibility }\end{array}$ & $\begin{array}{l}\text { Flex.3: } \\
\text { Grid } \\
\text { flexibility }\end{array}$ \\
\hline \multicolumn{4}{|l|}{ Context } \\
\hline Grid level & $\mathrm{a}$ & $\mathrm{a}$ & $\mathrm{b}$ \\
\hline Source & $\mathrm{a}$ & $\mathrm{d}$ & $\mathrm{b}$ \\
\hline Time frame & $\mathrm{a}$ & $\mathrm{c}$ & $\mathrm{a}$ \\
\hline Grid status & $\mathrm{b}$ & $\mathrm{a}$ & $\mathrm{b}$ \\
\hline Declaration & $\mathrm{a}$ & $\mathrm{a}$ & $\mathrm{b}$ \\
\hline Payment & $\mathrm{b}$ & $\mathrm{a}$ & $\mathrm{a}$ \\
\hline \multicolumn{4}{|l|}{ Usage } \\
\hline Goal & $\mathrm{a}$ & $\mathrm{b}$ & $\mathrm{a}$ \\
\hline Use case & $\mathrm{a}$ & $\mathrm{f}$ & $\mathrm{c}$ \\
\hline \multicolumn{4}{|l|}{ Actor } \\
\hline Source act. & $\mathrm{a}$ & $\mathrm{a}$ & $\mathrm{b}$ \\
\hline Use act. & $\mathrm{c}$ & $\mathrm{b}$ & $\mathrm{c}$ \\
\hline
\end{tabular}

Figure 2 - Example taxonomy configurations

It originates e.g. from tap position or open switches and can be used for example to improve the voltage quality.

Figure 2 highlights how these flexibilities differ with respect to all three dimension domains (Context, Usage, and Actor). The project members firstly found the flexibility classification useful to clarify their use cases and the solution scope of the different technical approaches to provide these flexibilities.

Moreover, the flexibility classification made potential timescale difficulties transparent. For example, if more actors can participate in the flexibility markets that trade flexibilities on different time scales, it may happen that in case of critical grid situations flexibilities are required for near real-time grid operations that were originally contracted for regular operations. An illustration of potential timescale conflicts of flexibilities is shown in Figure 3.

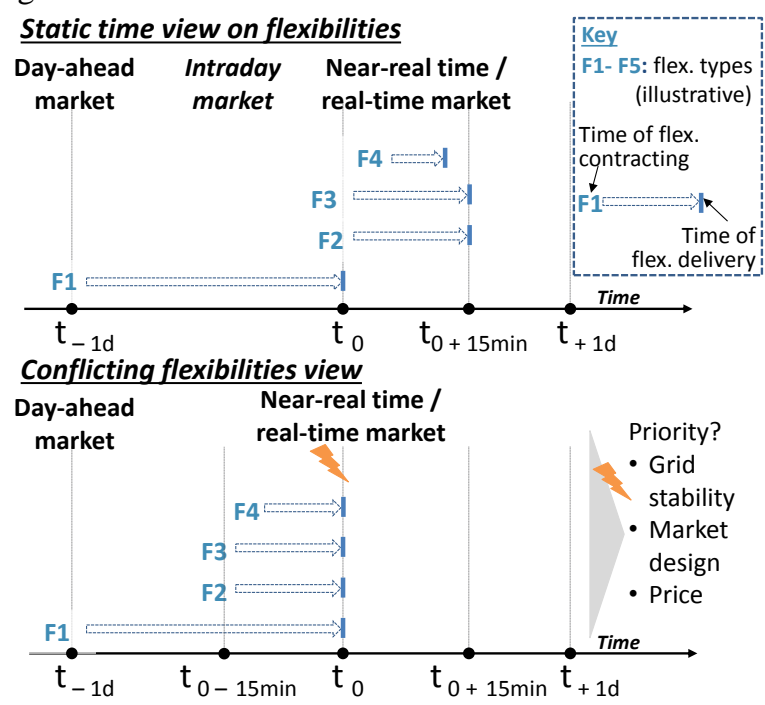

Figure 3 - Illustration of potential timescale conflicts of flexibilities
This requires retroactive settlement ways for conflicting flexibilities, real-time technical feasibility checks of flexibility bids, or some way of control of local market prices and prioritization mechanisms.

\section{DISCUSSION AND CONCLUSION}

The current taxonomy could be extended by other dimensions. For example, it could be useful to include a "technical realization" dimension that adds information on how the particular flexibility is provided (e.g. regarding the mathematical or technical solution). Furthermore, it could be extended by further dimensions with the parameter data that needs to be communicated between the actors in a particular use case. Examples for these parameters include the amount of power modulation, the duration, the rate of change, the response time etc.

Summarizing, the taxonomy in Figure 1 allows to describe flexibility types by specifying the context in which a flexibility arises and the actors that are involved. It could be used to foster communication between research and commercial partners in research projects, for example to more easily distinguish one use case from another. It could also help commercial actors to position their new products and solutions in comparison to existing solutions.

\section{ACKNOWLEDGEMENTS}

This work has been elaborated within the DREAM project, funded by the European Commission under FP7 grant agreement 609359, see www.dream-smartgrid.eu website for more information.

\section{REFERENCES}

[1] JRC, 2011, "Smart Grid projects in Europe: lessons learned and current developments", European Commission JOINT RESEARCH CENTRE (JRC) - Institute for Energy, 2011, ISBN 978-92-79-20487-6, Petten, The Netherlands.

[2] IEA, 2012, "Energy Technology Perspectives 2012: Pathways to a Clean Energy System”, International Energy Agency IEA, Paris, France.

[3] Caire, R. et al., 2014, "DREAM Reference Object Model and Dictionary”, Public Deliverable D5.1, DREAM Project, EU FP7 no 609359, 2014-03-11, p. 16.

[4] USEF, 2015, “USEF: The Framework Explained", USEF Foundation, Arnhem, The Netherlands.

[5] EURELECTRIC, 2014, "Flexibility and Aggregation: Requirements for their interaction in the market. A EURELECTRIC paper", EURELECTRIC, Brussels, Belgium.

[6] Nickerson, R. C., Varshney, U., Muntermann, J., 2013, "A method for taxonomy development and its application in information systems", European Journal of Information Systems, vol. 22(3), p. 338. 